\title{
Experience in correcting eating disorders in the clinic of mental illness
}

\author{
Ivan Romash11, Iryna Romash11, Oksana Kukhta1 , Kateryna Dzivak1, Hamna Ahmed² \\ 'Ivano-Frankivsk National Medical University, Ukraine \\ IIndependent Researcher, Republic of Maldives
}

\begin{abstract}
Introduction: Eating disorders - a class of psychogenic behovioral syndromes associated with eating disorders. The class of these disorders includes anorexia nervosa, bulimia nervosa, compulsive overeating, as well as several other disorders, which are included in the international classification, to section F 50-F 59.
\end{abstract}

Purpose: The purpose of our study is to trace the dynamics of individual eating disorders in patients with various mental illnesses under the influence of corrective therapy.

Methodology: Were examined 77 patients with various mental diseases who have had eating disorders. The first (I) group included 33 patients. They have added Metoclopramide at a dose of $20 \mathrm{mg} / \mathrm{day}$ to the main treatment. The second group (III) - 44 patients who received the drug Ondansetron at a dose of $4 \mathrm{mg} / \mathrm{day}$, respectively. The condition of all patients was assessed according to the following scales: Eating Attitudes Test (EAT-26), 36-ltem Short-Form Health Status (SF-36). Body mass index (BMI) was calculated to study the dynamics of weight. All examinations of patients were performed at the beginning and after 14 days of treatment.

Results: According to the EAT-26 scale the average score in the I group was $29 \pm 2.8$ points, and in the II $-30.1 \pm 2.4$, respectively. According to the SF-36 questionnaire, the average total score in the I group was - $69.5 \pm 1.8$ before treatment, $79.5 \pm 1.6$ - after treatment improved by $12.5 \%$ (p <0,05). In group II - $70.8 \pm 1.2$ and $89.4 \pm 1.5$, improving by $20.8 \%$, respectively $(p<0.05$ ). Under the influence of the therapy, the patients' manifestations of eating behavior decreased, which contributed to the growth of BMl: in group I - by $2.1 \pm 1.3 \mathrm{~kg}$, in group II - by $3.5 \pm 2.3 \mathrm{~kg}$, which is 1.6 times more.

Conclusions: The drug Ondansetron, intended for the correction of eating disorders, in combination with therapy of the underlying pathology, was likely to be more effective than Metoclopramide hydrochloride, which should be considered in practical psychiatry.

\section{Keywords}

Eating disorders, mental illness, Ondansetron, Metoclopramide

Address for correspondence:

Ivan Romash, MD, Ph.D., Assistant Professor, Department of Psychiatry, narcology and Medical Psychology. Ivano-Frankivsk National Medical University

e-mail: iromashr@gmail.com

This work is licensed under a Creative Commons AttributionNonCommercial 4.0 International License (CC BY-NC 4.0).

\section{(c) (i) (8)}

(C) Copyright: Romash, 2021

Submitted for publication: 13 April 2021

Revised: 27 July 2021 Accepted for publication: 02 September 2021

Licensee NDSAN (MFC- Coordinator of the NDSAN), Italy doi: https://doi.org/10.32437/mhgci.v4i2.127 


\section{Introduction}

Eating disorders - a class of psychogenic behavioral syndromes associated with eating disorders. The class of these disorders includes anorexia nervosa, bulimia nervosa, compulsive overeating, as well as several other disorders, which are included in the international classification, to section F 50-F 59 (IInytska, T., 2018). The impact of eating disorders is significant in terms of both economic costs and reduced welfare (Streatfeild, 2021). Each of the disorders has its peculiarities of development and course, but they all significantly impair the quality of life. (Galmiche, M., Déchelotte, P., Lambert, G., \& Tavolacci, M. P., 2019).

According to WHO experts, $70 \%$ of life expectancy and health depend on lifestyle, the most important factor of which is nutrition. The study of eating behavior as a psychological factor in the quality of human life is due to the needs of today because eating disorders are a very pressing issue. They are associated with severe medical and social consequences and have the highest mortality rate among all mental illnesses. According to the Eating Disorders Coalition (2016), today every 62 minutes at least one person dies from these disorders. The stigma around eating disorders reinforces misconceptions about their causes, inhibits efforts to promote knowledge to prevent, detect, and treat this type of disorder (Schaumberg, K. et.al, 2017). It is especially difficult to promote this knowledge among patients with mental disorders.

Therefore, the development of effective prevention programs is an urgent area of work. Therefore, this issue requires a comprehensive study of the peculiarities of the development of these disorders and the search for effective schemes for their correction.

\section{Purpose:}

To trace the dynamics of individual eating disorders in patients with various mental illnesses under the influence of corrective therapy.

\section{Design/Methodology/Approach}

The research was conducted based at the Municipal non-commercial enterprise "Precarpathian regional clinical center of mental health of Ivano - Frankivsk regional council» and «Pohonyansky psycho-neurological boarding house». 77 patients with eating disorders were examined against the background of various mental disorders, in which the syndrome of gastric dyspepsia was clinically dominant and was mainly manifested by nausea, vomiting, lack of appetite.

Depending on the prescribed treatment, patients were divided into two groups. The first (I) group included 33 patients who on the background of treatment of the underlying pathology, as an antiemetic received Metoclopramide (central dopamine antagonist) at a dose of $20 \mathrm{mg} / \mathrm{day}$, in the second (II) - 44 patients who received the drug Ondansetron (highly selective 5HT3 antagonist of serotonin receptors) at a dose of $4 \mathrm{mg} /$ day, respectively.

The study was comprehensive. All patients underwent a general clinical and physical examination, a survey on the scale "Eating Attitudes Test", which consists of 26 questions (English Eating Attitudes Test; EAT-26) to establish eating behavior and scaling on a short form of the questionnaire Medical Outcomes Study 36-Item Short-Form Health Status (SF-36), to assess the quality of life. Body (BMI) mass index was calculated to study the dynamics of weight.

All examinations of patients were performed at the beginning and after 14 days of treatment. Statistical analysis of the results was performed using a package of statistical functions of the program "Microsoft Excel".

\section{Results and discussion}

Among the examined patients were: 15 with anorexia nervosa, 26 patients who did not eat due to withdrawal syndrome due to chronic alcohol poisoning, 15 patients who refused to eat due to schizophrenia with imperative hallucinations, 21 patients were diagnosed with acute enteral poisoning by alcohol surrogates.

In $38.0 \%$ of all subjects, there was a history of lack of compliance with previous therapy, which was manifested by a deficit of body weight. According to the methodology of the EAT-26 scale, a result with a score of $\geq 20$ points should be considered an eating disorder. As a result of our study, eating disorders were confirmed in both groups. The average score in the 1st group of patients was $29 \pm 2.8$ points, and in the second $30.1 \pm 2.4$, respectively.

According to the SF-36 questionnaire, the average total score in the first group was - $69.5 \pm$ 1.8 before treatment, $79.5 \pm 1.6$ - after treatment improved by $12.5 \%(\mathrm{p}<0,05)$. In group $\|-70.8 \pm$ 1.2 and $89.4 \pm 1.5$, improving by $20.8 \%$, respectively $(p<0.05)$, which proves the higher effectiveness of Ondansetron compared with

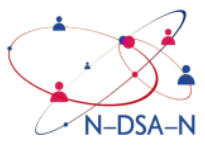


standard therapy with Metoclopramide hydrochloride. Under the influence of the therapy, the patients' manifestations of eating behavior decreased, which contributed to the growth of BMl: in group I - by $2.1 \pm 1.3 \mathrm{~kg}$, in group $\|$ - by 3.5 $\pm 2.3 \mathrm{~kg}$, which is 1.6 times more.

\section{Limitations of the study $\backslash$ Strengths of the study:}

The practical value of the results of our study can be used to address scientific and practical issues aimed at improving the correction of identified eating disorders in patients with various mental illnesses, which in turn directly affects the quality of life of such patients, their physical and social functioning.

\section{Conclusions (and Future Work)}

Thus, the drug Ondansetron, intended for the correction of eating disorders, in combination with the therapy of the underlying pathology, was likely to be more effective than Metocolopramide hydrochloride

\section{Conflict of interest}

The authors declare that they have no conflict of interest.

\section{References}

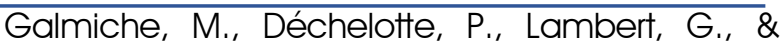
Tavolacci, M. P.. (2019). Prevalence of eating disorders over the 2000-2018 period: a systematic literature review. The American Journal of Clinical Nutrition, 109(5), 1402-1413. https://doi.org/10.1093/ajcn/nqy342

Inytska Tetyana (2018). Eating Disorders: Myths and Facts [Електронний ресурс]. NeuroNews. № 4-5 (97). [Electronic resource]. - Access mode: URL:https://neuronews.com.ua/ua/archive/201 8/4-5\%2897\%29/pages-6-7/rozladiharchovoyi-povedinki-mifi-ta-fakti\#gsc.tab $=0$

Schaumberg, K., Welch, E., Breithaupt, L., Hübel, C., Baker, J. H., Munn-Chernoff, M. A., Yilmaz, Z., Ehrlich, S., Mustelin, L., Ghaderi, A., Hardaway, A. J., Bulik-Sullivan, E. C., Hedman, A. M., Jangmo, A., Nilsson, I. A. K., Wiklund, C., Yao, S., Seidel, M., \& Bulik, C. M.. (2017). The Science Behind the Academy for Eating Disorders' Nine Truths About Eating Disorders. European Eating Disorders Review, 25(6), 432450. https://doi.org/10.1002/erv.2553

Streatfeild, J., Hickson, J., Austin, S. B., Hutcheson, R., Kandel, J. S., Lampert, J. G., Myers, E. M., Richmond, T. K., Samnaliev, M., Velasquez, K., Weissman, R. S., \& Pezzullo, L. (2021). Social and economic cost of eating disorders in the United States: Evidence to inform policy action. The International journal of eating disorders, 54(5), 851-868. 